\title{
Introduction: Modeling the Pacific Ocean
}

\author{
Sebastian Vehlken ${ }^{a}$, Christina Vagt ${ }^{b}$, Wolf Kittler ${ }^{c}$ \\ Keywords: media theory, oceanography, environmental humanities, computer simulation, epistemology of modeling and simulation, pacific ocean \\ https://doi.org/10.1525/001c.21997
}

\section{Impossible Pacific}

According to climate models, the Pacific Ocean, the body of water that encompasses one-third of the earth's surface, impacts global climate to a large extent. Geographically, the Pacific borders on three continents-Australia, Asia, and the Americas-and it has been up until today the center stage of geopolitical interests and conflicts, cold and hot wars. Because of its dimensions and location, the Pacific is not simply an object of scientific research but also occupies a central place in global history, world literature, and postcolonial theory. Since it never was conceived as a political or a cultural unit such as the Mediterranean, "a landlocked sea," a sea surrounded by mountains (Braudel [1972] 1995, 25), it defies age-old concepts of European historiography. Whoever tries to address "the" Pacific has to reckon with a multitude of local and heterogeneous living environments and historiographies, all of which contribute to a scientific "new ocean world picture." As such, the study of the Pacific opens up (and ties together) peculiar perspectives on a whole range of forms of knowledge. Operating on the scale of global interactions, this study explores scientific as well as governmental modes and techniques of

\footnotetext{
a Sebastian Vehlken is a media theorist and cultural historian at Leuphana University Lüneburg (Germany) and Senior Researcher at the Institute for Advanced Study on Media Cultures of Computer Simulation (MECS). His areas of interest include the theory and history of computer simulation and digital media, media cultures of futurology, and oceans as media environments. His current research project Hypotheticality - Computer Simulation and Nuclear Energy 1960-80 explores the intersections of futurology and Fast Breeder Reactor programs. He is the author of Zootechnologies - A Media History of Swarm Research (Amsterdam University Press 2019), and co-editor of Neighborhood Technologies - Media and Mathematics of Dynamic Networks (Diaphanes/Chicago University Press 2015).

b Christina Vagt is Associate Professor of European Media Studies at the UCSB's Department of Germanic \& Slavic Studies. She teaches history and theory of media, science and literature, as well as European philosophy. Her research focuses on epistemic and aesthetic relations between sciences and humanities and the role that media and technology play in it.

Before joining UCSB in 2017, she taught History and Theory of Culture at Humboldt Universität zu Berlin, Literature and Science at Technische Universität Berlin and History and Theory of Media at Bauhaus Universität Weimar.

Books: Geschickte Sprünge. Physik und Medium bei Martin Heidegger (Diaphanes 2012); Action at A Distance, edited together with John Durham Peters and Florian Sprenger (Minnesota Uni. Press / Diaphanes 2020); Verhaltensdesign. Technologische und ästhetische Programme der 1960er und 1970er Jahre, edited together with Jeannie Moser (Transcript 2018), and The Afterlife of Systems, a special issue of communication+1, edited together with Florian Sprenger.

c Wolf Kittler studied German and Romanic Languages and Literatures at the university of Freiburg, Germany. He is Professor for German and Comparative Literature at the University of California, Santa Barbara. He taught at the universities of Erlangen-Nürnberg, Freiburg, Munich, Konstanz, Graz, Siegen, Cornell, and Basel.

He has published books and essays on literature, art, philosophy, the history of science, the history of warfare, and media theory. His recent publications include articles on Impressionism as an effect of the chemical dye industry, on the history of the Greek alphabet from Euripides to Plato, on early wireless technology, on music in Jean Jacques Rousseau's work, and on the early history of the term risk.

Works in progress: On Wings of Light. A Cultural History of Telecommunication, and Echo's Echoes. From Freud to Lacan.
} 
"controlling" the Pacific Ocean, the epitome of the unknowable object or space on this planet. As Matt K. Matsuda puts it in his persuasive article The Pacific (2006, 759-60):

The Pacific is not lacking in grand conceptual vocabularies. As Braudel framed the Mediterranean as a complex of maritime civilizations and Paul Gilroy cogently articulated the diasporic logic of the Black Atlantic, so the "Pacific" has been historically reimagined many times: from an ancient Polynesian and early modern Magellanic space of transit, to an Enlightenment theater of sensual paradise, to a strategic grid of labor movements and military "island-hopping," to a capitalist basin, the key to a Pacific Century of emerging wealth and "globalization" at the end of the last millennium.

Matsuda tries to match such established grand narratives with a focus on the importance of "small islands, large seas, and multiple transits" for approaching Pacific history. By advocating a similar "oceanic approach," Modeling the Pacific Ocean, this special issue (or rather stream) of Media+Environment also counters the so-called "rim approach," which is concentrated on the economic and political power relations of the maritime states of the (northern) Pacific (the United States, China, Japan, Korea, and the nations of Southeast Asia).

However, we seek to complement Matsuda's cultural historical perspective with media-technological aspects: a detailed and media-specific exploration of oceanic knowledge, histories, and narratives in this issue challenges conventional modes of objectification, stratification, and analysis in both the sciences and the humanities. Instead of lamenting a colonization of ocean space through existing terra firma approaches and technologies, we focus on the specificities of oceanic media technologies that may alter and destabilize established scientific methodologies on land. Regarding "the large seas" as a knowledge space that is downright defined by the features that disturb and disrupt the modes of access to that very knowledge, we ask what scientific methods, media technologies, and procedures are necessary to account for the multiplicity of interfering phenomena in knowledge production processes. Taking an "oceanic approach" means to assess novel fields for scientific procedures whose "reality filters" significantly differ from land-based conceptions and modes of operation.

As Stefan Helmreich points out in his article on the Floating Instrument Platform (FLIP), many large-scale oceanographic research projects depend on the projection of geopolitical power: they depend on the fact that access to small islands across the oceanic space serves as a prerequisite for gathering widespread observational data. Quite fittingly, Ruth Oldenziel $(2011,16)$ has referred to US island territories as "naval nodes for the control of ocean space." Helmreich shows how ocean observatories like FLIP serve as similar nodes: the unique research platform becomes a lens through which to explore wave 
science, its ties to militarism and colonialism, and its everyday practices. And Helmreich's reflections on the operability and different meanings of "flip" interweave these material politics with the epistemological underpinnings of observational ocean media.

The scientific study of oceans always has a geographical and geopolitical index - a fact that we try to articulate in the title of this issue. Modeling the Pacific Ocean originated in an international conference held at UC Santa Barbara in 2019, and it largely draws from scientific networks within academic research communities and oceanographic institutions in California. Obviously, this has led to a certain "Pacific bias." Nevertheless, this predominant concern with the Pacific Ocean is tied to a more general "oceanization," where the Pacific serves as a scientific object that connects to and extends into the remaining worldwide ocean space — as a particular object and, at the same time, a universal model for "oceans."

As Martin W. Lewis (1999), in his article "Dividing the Ocean Sea," so aptly argued, to speak of separated oceans at all is impossible. At the beginning of his article, Lewis marvels about the surprisingly exact depiction and differentiation of the world's oceans to be found in atlases, almanacs, encyclopedias, and further sources of geographical information-as if each of them were an "unambiguously bounded body that one could simply measure" $(1999,188)$. In fact, despite the respective claims of exactness in standard sources, their quantifications differ considerably: Lewis $(1999,188)$ contrasts the "precisesounding 64,186,300 square miles" of the World Almanac's Pacific (Famighetti 1997, 593) with the almost 400,000 square miles smaller Pacific in Goode's World Atlas (Goode 1990, 250) and the more than 5,000,000 square meters larger ocean of the Encyclopedia Britannica (albeit "with marginal seas included") (Mero 1989, 125).

Lewis argues that such positivistic attempts to divide oceans into apparently clear-cut units whose boundaries could be objectively defined and analyzed "disguise the conventional nature of their construction" (Lewis 1999, 189). And in a historical journey of "ocean orderings," which span from ancient Greece to modernity, he endeavors to deconstruct the European worldview with its conventional schema of geography (see Lewis 1999, 189). His analysis shows how malleable the designations, names, and separating principles of maritime space have been throughout the centuries; how they were constantly reformulated in connection with the inventions of novel nautical instruments, mapping techniques, or geographical discoveries; and how they shifted from one predominant "ocean world picture" to another: "[T]he Western conceptualization of the oceans may be [...] described as one of aimless wanderings," depending on the respective epistemic regimes of different historical circumstances (Lewis 1999, 210). These pictures include classical worlds bounded by an ocean; medieval geometrical arrangements; the first basin perspectives of early modern times as well as the ocean-arc concept of 
Enlightenment cartography, "in which oceanic designations are displaced from basin cores to skirt or wrap around landmasses" (Lewis 1999, 203); and competing modern perspectives such as Élisée Reclus's (1872) propagation of a globe-girdling "Southern Ocean" (with the Atlantic, Pacific, and Indian Oceans as mere northern embayments) as well as the (nowadays widely accepted) three-ocean model, which the oceanographer Otto Kümmel proposed in 1897 . This leads Lewis to a sober yet epistemologically optimistic conclusion:

In the final analysis, perhaps it is pointless to ask whether oceans have improved, declined, or merely changed. What is certain is that no standard textbook definitions can ever reveal "real" divisions across the undivided Ocean Sea. Dividing up sea space in a regular manner allows effective communication, but it does so by guiding our imaginations along certain preset pathways, pathways that reflect specific cultural and political outlooks. Perhaps the most effective way to expose those outlooks is to experiment with novel modes of mapping. On standard equatorially based world maps, discrete ocean basins do indeed leap to the eye. But on polar-based projections-which are almost as rare today as they were in the time of Cassini-different patterns emerge. One of the best ways to see the world afresh-and to reveal a global sea-is simply to invert a globe. (Lewis 1999, 211)

Modeling the Pacific Ocean subscribes to a similar experimental approach-not by creating novel geographical mappings but by juxtaposing and connecting "Pacific perspectives" from the sciences and the humanities alike that chart novel epistemological, historical, and media-theoretical modes of engaging with oceans.

\section{Thinking and Seeing through the Ocean}

It is a well-known and often noted truism that the "earth" is not a good name for the planet we inhabit. For a long time, the pathless, incomprehensible, and immeasurable space, dynamics, and materiality of oceans could be addressed only in reference to a terra firma: to a theoretical and methodological mainland whose geographical orientations and spatial logics also framed the scientificsystematic and cultural-semantic attempts to hedge the "vast expanses" (Rozwadowski 2018). That the world-spanning oceans have come to the attention of science and the public more recently is an effect of the globalization of economic and social systems, on the one hand, and the resulting ecological challenges, which can be mastered only globally, on the other. Such earth-spanning developments have changed the status of the oceans not only in the natural and the technical sciences but also in the humanities and the social sciences. Modeling the Pacific Ocean is dedicated to 
these epistemological shifts, with a special emphasis on the technical media by means of which the oceans have been and are being monitored, charted, and analyzed.

Within the past century, the relationship between the oceans and what used to be terra firma has changed drastically. New transoceanic exchange relations and communications have emerged (see, e.g., Steinberg 2001; Starosielski 2015; Klose 2015; Edwards 2010); "land-based" concepts and logics of exploration and development have been replaced by maritime endeavors and concepts (see, e.g., Gabrys 2016; Chang 2012; Helmreich 2011b; Batra and Messier 2008; Klein and Mackenthun 2004); and extraterrestrial habitats and life-forms are being developed (see, e.g., Rozwadowski 2018; Helmreich 2009). In short, the oceans are increasingly shaping our modes of existence on terra firma, be it as a sphere that generates or even enables exchange relations, as an absorber of an immense amount of civilization segregation, or as a new source of scarce material reserves. The oceans play a crucial role in global ecological and economic systems and their cycles, contaminations, and possible future tipping points. Not only do they function as a prominent object of knowledge, they also constitute a figure of knowledge that fosters new perspectives and reflections on social, economic, or cultural phenomena and processes on terra firma. And the oceans are at the center of a critical environmentally oriented thinking, which-due to the vastness of this (non)object, its challenges and potentials - can be mobilized only by a joint effort of thinking across the disciplinary boundaries of the sciences and the humanities and social sciences.

We understand this stream of Media+Environment as one such interdisciplinary effort to study the conditions under which the oceans are currently being reconceptualized in light of radically new techniques. We are trying to trace the way in which the (once upon a time) "vast, and formless oceans" are now being shaped abstractly and artificially—through the sensors of vast arrays of measuring instruments, through the statistical patterns that are being extracted from the data these instruments collect, and in the virtual spaces of computer simulations that mine the databases for future possibilities. For a general analysis of one such technique-namely, generative adversarial networks-see Fabian Offert's essay "Latent Deep Space: GANs in the Sciences.”

Yet the new techniques and methods of data collection, analysis, and processing also throw new light on the past and the traditions of oceanic societies. As Sabine Höhler shows in her contribution to this stream, long before climate patterns such as El Niño were registered by science and satellite technology as global climate phenomena, knowledge of extreme cyclical weather events already circulated in the form of local stories among the people of South America, Indonesia, and Asia. And Tyler Morgenstern, in his examination of a wireless telegraphy network in the Hawaiian Islands around the turn of the twentieth century, analyzes how the local planter class used this 
communications technology to reshape relations between Hawai'i and the mainland United States through colonial models of scale and proximity. $\mathrm{He}$ argues that modeling never escapes its material predicates, and thus never reduces to pure symbology or ideation.

Modeling the Pacific Ocean deals with probes, drifters, and acoustic or microwave-based scanning methods, technologies of multispectral in situ data acquisition that-compared to previous forms of experimental research such as, for instance, marine biological research stations-are characterized by their increased mobility and their decentralization. We aim to thematize how these instruments produce data about macrosystemic interrelationships that can, then, be processed, represented, and replicated in mathematical models and computer simulations. As Libe Washburn points out in his contribution, the difference between observing the ocean and modeling it is crucial for the oceanographer because "we see the ocean through the ocean, and it is always kind of obscured and noisy." Moreover, as Eckart Meiburg explains in his presentation, it is a long way from gathering satellite data and conducting field observations before something as fluid and dynamic as the ocean can be simulated by a computer. By juxtaposing experimentation and modeling, Modeling the Pacific Ocean attends to tensions, overlaps, and syntheses between experimental practice, datafication, and theoretic-formal model building within science and engineering, on the one hand, and their interactions with the socioeconomic dimensions of political decision-making processes, on the other. Whoever aims at conserving marine life has to model the behavior not only of fish but also that of fishermen, according to Douglas Steigerwald's presentation. And as Lisa Han argues in her critical exploration of the media history of seismic seafloor surveys, epistemological questions related to sonic techniques of knowledge production are intricately linked to the environmental effects of such submarine "bangs."

Oceans play a multidimensional and increasingly detailed role in global circulation models and climate simulations. Their importance is evident in phenomena that range from $\mathrm{CO}_{2}$ storage capacities and acidification to polar ice melting and rising sea levels, increased water temperatures, and extreme weather phenomena. As Samantha Stevenson elaborates in her contribution, climate science has placed oceanography and its study of ocean dynamics at the center of discussions about the effects of anthropogenic climate change. Meanwhile, resource companies are searching the ocean floor for new resources, which are seen as a prerequisite for those "future technologies" and all those green economy and green growth concepts, with which, it is hoped, the extent of climate change could be kept within tolerable limits (see, e.g., Economist Films 2020; World Bank 2012; Bowen and Fankhauser 2011; European Commission 2010; Green New Deal Group 2008). Environmental scientists are investigating the pollution of the world's oceans by such relatively new waste products as more or less poisonous chemicals, radioactive substances, or plastic debris, often with far-reaching reverberations in the 
public sphere (see, e.g., Lebreton et al. 2018; van Sebille 2013; van Sebille, England, and Froyland 2012; Gabrys, Hawkins, and Michael 2013). Meanwhile, a variety of NGOs and initiatives are dedicated to addressing these problems and protecting or cleaning up the oceans (see Mambra 2019 for an overview of fifteen leading institutions for ocean preservation). The most prominent of these various programs to date is the large-scale initiative of the UN Ocean Science Decade for Sustainable Development, which started on January 1, 2021, with a call for programs, projects, and other activities to help meet its vision of defining and developing "the science we need for the ocean we want” (International Science Council 2020).

In addition to our interest in current advances in oceanography, climate science, and environmental policy, we are also following current discourses in the humanities-especially in media and culture studies-by asking in what way oceans can be paradigmatically (and paradoxically) conceptualized as both the greatest medium and the limit point of any possible media (see Peters 2015): oceans are mediums in the sense of both "substance" and "environment," and it is their materiality and spatiality that pose a particular challenge to media in the sense of modern communication and measuring systems, whose cables, sensors, and electromagnetic communication systems often don't work for long or not at all in a salty water body full of living microorganisms. In recent years, a number of approaches from the perspective of anthropology, social sciences, history and history of science, critical infrastructure studies, and environmental media studies, among others, have suggested various possibilities of thinking through the ocean (e.g., Helmreich 2009, 2011b, 2011a, 2016; Höhler 2014; Jue 2020; Rozwadowski 2005, 2018; Shiga 2013, 2016; Starosielski 2015). Thus, in addition to a long tradition of thematizing oceans as eminent geopolitical factors, as emancipatory postcolonial study objects, or as cultural-theoretical metaphor machines, novel research initiatives put a high emphasis on the (deep) blue seas in order to assess the repercussions between the materialities of emerging (media) technologies and networks, their impact on the fabric and distribution of global sociopolitical and economic power, changing conditions of possibility of past and current oceanographic knowledge production, and resulting transformations in the means of (re)presenting the oceans and other largescale natural phenomena. At the same time, popular productions such as the TV series The Blue Planet (BBC 2001, 2018) or the documentary Oceans (Perrin 2009) reactivated traditional imaginaries of the oceans as (still) pristine "extraterrestrial spaces," not least by means of innovative film and CGI techniques (even if Blue Planet II [2018] also includes agonizing examples of the devastating environmental effects of climate change and pollution on ocean habitats and marine life-forms). However, whereas approaches that explore media "in" the ocean make the ocean seem like a mere container or external environs, a perspective on thinking "through" the ocean, as Melody Jue has 
pointed out, positions the ocean as an optical and sensory medium that the observer actively orients within (Jue 2020, 22). Briefly put, in these approaches the materiality of oceans is not the bug but the feature.

Modeling the Pacific Ocean expands this discourse on the ocean's mediality by explicitly connecting it with natural and technical ocean sciences and oceanographic research-taking the latter not as objects of detached humanistic reflections or historical classifications, but rather as driving factors for theory building. The media theoretical thematization of current techniques of computer-aided modeling and simulation thus seems to us to be particularly suitable for initiating a "thinking through the ocean" by explicitly interweaving epistemologies, methods, knowledge objects, and knowledge figures of the oceanic in the natural sciences, in the social sciences, and in the humanities, and for casting them into a sustainable structure. For it is via modeling and computer simulation techniques that fictional elements, productive references to nonknowledge, the time dependency of processes, an awareness of alternative scenarios, and a provisional nature of results find a common home-an epistemological home that always already merges scientific and humanistic knowledge production strategies.

\section{Media Theory and the Ocean}

As Marshall McLuhan knew all too well, media theory is occasionally a fishy business. It is no coincidence that McLuhan, having grown up in the "backwaters" of Canada (in the words of his biographer Philip Marchant), sent a "message to the fish" in 1968 that begins with the following consequential observation: "One thing about which fish know exactly nothing is water. ... [T] he fish has an essential built-in potential which eliminates all problems from its universe. ... Such is not, by any means, the case with man" (McLuhan and Fiore 1968, 175). Under newly emerging (media-)technical conditions, that is, our relationship to the environment can hardly be defined as being a perfect fit. Rather, it is characterized by processes of creating this world and creating ourselves within it. In order to comprehend these processes, in turn, we need to create "anti-environments" (McLuhan and Fiore 1968, 177) - that is, we need to distance ourselves from our own situation. It is only from such a position that humans can yank themselves out of the water, so to speak, and master the laws of new media worlds like surfers on the ocean's crests (by this McLuhan meant media interfaces) - surfers who are ever in pursuit of the perfect (electromagnetic) wave.

In an attempt to further deepen McLuhan's allegorical essay, Modeling the Pacific Ocean endeavors to explore the relationship between humans, media, and seawater by pursuing the following set of questions: What happens when media theory no longer operates from the surface but rather jumps off its surfboard into the cold water, thus inverting the perspective to look up from below the water surface to the surfboard-based anti-environments above? What happens when the surfing overview of the analytical anti-environment 
must thereby become effective within this very environment? Such questions are meant to spur an investigation of the specific medial relations that arise, come in between, and become effective when oceanic research attempts to understand the dynamic flurries of oceans as objects of knowledge. How does an understanding of these dynamics constitute itself in a novel and different way in relation to certain media-technical parameters? In what ways do the destructive, distortive, unruly, and opaque factors of the "immediate" water environment of fish (as McLuhan called it) limit the applicability of technical systems of observation? How, beyond the limiting surface of the sea, are new surfaces of reflection created by more synthetic media-technological modes of thinking through oceans than in McLuhan's "anti-environments" - that is, entirely unmetaphorical "data oceans" based on a variety of novel sensortechnological embeddings, and projected in sophisticated four-dimensional computer simulation models? And finally, which new modes of impermeability and opacity appear when working with digital ocean models and simulations?

While the oceans, since ancient times, have always evoked a degree of horror about the unfathomable and continue to bear a level of "blurriness" in its most literal sense until today, the inquiry we envision turns toward approaches that embrace the productivity of disturbance. This also represents a break with conventional methods of colonizing oceanic spaces: no longer primarily addressed as unmanageable and inaccessible surfaces or depths, they can now be understood as dynamic mixtures of laminar and turbulent currents and dynamic exchange processes. In philosophical terms, this view is perhaps most forcefully formulated by the French mathematician and philosopher Michel Serres. In his writings, it is with oceanic metaphors and images that he maps the "thermodynamic awakening" of new sciences, which, around the turn of the twentieth century, atomized mechanistic worldviews and rational knowledge strategies into clouds and storms. For Serres, the ocean is the guiding allegory of sciences increasingly devoted to the stochastic. Hence, it conceptualizes knowledge as a random distribution with multiple processes of structure formation:

Renversement : les vieux systèmes ordonnée, au contraire, ne sont plus que des îles rares sur une mer qui ne s'arrête pas [...]. Et s'il y a des choses, des corps et des messages, du sens, des structures en ordre ou même des systèmes [...] ce n'est que sous figure d'archipels. Voici des sporades ensemencées sur l'océan ouvert, informe. (Serres 1977, 10)

(Reversal: the old ordering systems are mere islands in a sea that doesn't stop. ... And if there are things, material things, and messages, if there is sense, ordered structures or even systems..., then only in the form of archipelagos. Sporadic islands scattered across the open, formless ocean. [Translation by the editors.]) 
Oceans thus stand for a radical break in the history of science, a new distribution of knowledge, where thermodynamics and hydrodynamics, quantum physics and later information theory, as new leading sciences, explore areas that were previously classified and excluded as beyond the real: "Il y a orage sur la vieille science et la vieille philosophie, coup de vent, nuage, météore, tsunami, transgression, au sens de transgression des eaux" (Serres 1977, 11). (There is a storm over science and the old philosophy; there are gusts, clouds, the weather with all its phenomena, tsunamis, flash floods, transgression in the sense of water, that transgresses [its shores]. [Translation by the editors.])

Serres's departure toward new knowledge culminates in the physical oceanography of the second half of the twentieth century and in the climate sciences of the last four decades, and it is within this new distribution that a turn to media of modeling and computer simulation occurred. Serres's oceanic thinking is akin to what Stefan Helmreich has termed "athwart theory" - "that is, a tacking back and forth between seeing theory as explanatory tools and taking them as explanatory tools and taking them as phenomena to be examined" (Helmreich 2011b, 138). And it is this kind of thinking that informs our approach in Serres's wake as well. "Operating athwart theory" implies a critical stance on what he calls an "oceanization" of thinking in historical and cultural analyses. Characterized by a turn to the material aspects of seawater, these analyses initiate a rephrasing of sociality in terms of fluidity, currents, or circulations, and with respect to globally flowing things-capital, refugees, weapons, drugs, fish, and so on (see Helmreich 2011b, 137). Such analyses can comprise a lament about an alleged sociopolitical deracination, perhaps most prominently expressed in Zygmunt Bauman's Liquid Modernity (2000), as well as the embrace of liberating views, an example of which would be John Kurien's suggestion that we engage in multiperspectival analyses of "seacosystems" (see Kurien 2002). Athwart theory, like our own thinking through oceans, in contrast, is characterized by a recursive relation between the ocean's materialities, their media-technological measurements, and theory making. Helmreich, in one of his texts, highlights this position with regard to the example of the 2010 Deepwater Horizon oil spill:

The spill became available to comprehension because of an intermingling of the empirical and the theoretical. Awareness of the spill and its extent emerged at a variety of levels, from shoreline experiences of a slick arriving on beaches to fishers' and shrimpers' experiences of their poisoned supply chain. But the phenomenon was also made apprehensible through models - simulations that use data from satellites and submarine sensors and that plug these into algorithms that model flow and currents. The very "empiricity" of the spill-including as a "national" or "global" event-became manifest through machines instantiating theories of seawater behavior. (Helmreich 2011b, 138) 
With its emphasis on the media-material features of modeling and computer simulation, especially in physical oceanography, this issue of Media+Environment is explicitly meant to connect to detailed studies that describe concrete connections, boundaries, and overlappings between the materialities and immaterialities that constitute ocean sciences and the new oceanic world picture of today by such authors as Stefan Helmreich (2007, 2009, 2011b, 2011a, 2016), Naomi Oreskes (2014), Paul N. Edwards (2010), Nicole Starosielski and Janet Walker (2016), Helen Rozwadowski (2005, 2018), or Lisa Parks (Parks and Starosielski 2015), as well as to a number of recent explicitly speculative renderings of a thinking through oceans. In Wild Blue Media, Melody Jue (2020) attempts to speculatively "submerge" familiar concepts in new media studies, here with reference to such terms as "interface, inscription, and database," in order "to test how we think about environmental media and mediation underwater" (Jue 2020, 22). As she demonstrates in her contribution to this issue, not only do media formats and aesthetic practices play an active part in scientific configurations, but even seaweeds can be understood as agents in the distributed media systems of satellite imaging.

Jennifer Gabrys, in her meticulous studies of environmental sensing systems (Gabrys 2016), gives her chapter on ocean sensing a speculative twist as well:

$\mid$

This geo-speculative inquiry is then less focused on explaining the origins of the garbage patch. Instead, the geo-speculation developed here considers how much of the uncertainty around the gyres involves exploring what kind of earth or ocean object the garbage patch is, and even more, what potential events and effects may unfold through this shifting formation. (Gabrys 2016, 139)

As he explores such functions as transmission, storage, and recording in environmental "elements" like geological strata, the atmosphere, and (ocean) waters and treats them as kinds of media infrastructures in his already canonical The Marvelous Clouds, John Durham Peters skillfully distances himself from a materialist perspective on media, and he conducts a series of fascinating thought experiments in order to find "the homeland of media" and mediation

in the elusive and recalcitrant...: The emphasis on materiality is a healthy counterbalance to the digital hype that we are moving from a world of atoms to one of bits, but we should not forget that immaterial (symbolic) operations lie at the heart of our oldest and most taken-for-granted media. Media, like human beings, are always in the middle between sea, earth, and sky. Media studies is thus a form of philosophical anthropology, a meditation on the human condition, which also means a mediation on the nonhuman condition. (Peters 2015, 12) 
Consequently, in his contribution to Modeling the Pacific Ocean, Peters dives into the history of literary and oceanographic cartography and shows how "the" Pacific is a conglomerate of names, maps, and imaginations.

In conclusion, the need to conduct thought experiments, to speculate, or even to fantasize about alternative modes and technologies of scientific inquiry as well as alternative narratives, histories, names, and agencies in the presence of increasingly catastrophic scenarios of climate change is more than a subjective mode or a play with words. But in order to tap into possible transformative forces of an oceanic media theory, it would have to be continuously informed by and fed back into scientific inquiries.

How such a dialogue can be put into effect is an open question. Modeling the Pacific Ocean started as an interdisciplinary conference in 2019, in which scholars from the sciences, engineering, and the humanities were equally engaged, trying to translate their specific modes of oceanic inquiry and presentation to the others. What worked so well as a live event in times of international conference travel, intense discussion rounds in crowded rooms, and relaxed conversations around the dinner table posed a new challenge when it came to publishing the conference proceedings in written form: While scientists and engineers usually present their models in the form of condensed mathematical formulas or statistical data, scholars of the humanities write essays and entire books. While one side concretizes, individualizes, and qualifies, the other abstracts, generalizes, and quantifies. An interdisciplinary conference is at the same time the greatest of all conferences and the limit point of conferencing as such because there is a media problem in its midst: one half can only speak about what the other half writes about, and vice versa. Modeling the Pacific Ocean accommodates this problem by presenting written essays alongside spoken presentations. As an open access publication platform, Media+Environment allows our stream to continue beyond the launch of the first batch of essays and video lectures in 2021, to which we hope to successively add more diverse perspectives and presentations.

\section{Acknowledgments}

This issue of Media+Environment originated in the international, interdisciplinary conference Modeling the Pacific, which was held at UC Santa Barbara from October 10 through October 12, 2019. It is funded by MECS Institute for Advanced Study on Media Cultures of Computer Simulation, Leuphana University Lueneburg, Germany (German Research Foundation Project KFOR 1927) and the Carsey Wolf Center at UC Santa Barbara, and was also sponsored by $M+E$. Our warmest thanks go to our contributors, who agreed to develop their conference papers into journal articles, or to give us permission to create a video stream of their conference presentations. We also thank Bernhard Siegert (Bauhaus-University Weimar) for insightful conversations about the Pacific and its "impossibility", as well as for valuable 
references. And last but not least, we are indebted to $M+E$ editors Janet Walker, Alenda Chang, Adrian Ivakhiv, and coordinating editor Stephen Borunda for their enthusiastic support of this publication, and to the anonymous peer reviewers who assessed the articles in this issue. Ahoy! 


\section{REFERENCES}

Batra, Nandita, and Vartan P. Messier. 2008. "The Multitudinous Seas: Matter and Metaphor.” In This Watery World: Humans and the Sea, edited by Vartan P. Messier and Nandita Batra, 1-19. Newcastle: Cambridge Scholars.

Bauman, Zygmunt. 2000. Liquid Modernity. Cambridge: Polity.

BBC. 2001. The Blue Planet.

- - - 2018. Blue Planet II.

Bowen, Alex, and Samuel Fankhauser. 2011. "The Green Growth Narrative: Paradigm Shift or Just Spin?” Global Environmental Change 21 (4): 1157-59. https://doi.org/10.1016/ j.gloenvcha.2011.07.007.

Braudel, Fernand. (1972) 1995. The Mediterranean and The Mediterranean World in the Age of Philip II. Berkeley: University of California Press.

Chang, Hasok. 2012. Is Water H2O? Evidence, Pluralism and Realism. Dordrecht: Springer.

Economist Films. 2020. Can Deep-Sea Mining Help the Environment? https://www.woi.economist.com/can-deep-sea-mining-help-the-environment/.

Edwards, Paul N. 2010. A Vast Machine: Computer Models, Climate Data, and the Politics of Global Warming. Cambridge: MIT Press.

European Commission. 2010. "EUROPE 2020 - A Strategy for Smart, Sustainable and Inclusive Growth.” https://ec.europa.eu/eu2020/pdf/ COMPLET\%20EN\%20BARROSO\%20\%20\%20007\%20-\%20Europe\%202020\%20-\%20EN\%20version.pdf.

Famighetti, R. 1997. The World Almanac and Book of Facts. Mahwah: World Almanac Books.

Gabrys, Jennifer. 2016. Program Earth: Environmental Sensing Technology and the Making of a Computational Planet. Minneapolis: University of Minnesota Press. https://doi.org/10.5749/ minnesota/9780816693122.001.0001.

Gabrys, Jennifer, Gay Hawkins, and Mike Michael, eds. 2013. Accumulation: The Material Politics of Plastic. Culture, Economy and the Social. Abingdon, Oxon: Routledge. https://doi.org/10.4324/ $\underline{9780203070215 .}$.

Goode, J.P. 1990. Goode's World Atlas. Edited by E.B. Espenshade Jr. Chicago: Rand McNally. Green New Deal Group. 2008. A Green New Deal. London: New Economics Foundation. https://neweconomics.org/uploads/files/8f737ea195fe56db2f_xbm6ihwb1.pdf.

Helmreich, Stefan. 2007. "An Anthropologist Underwater: Immersive Soundscapes, Submarine Cyborgs, and Transductive Ethnography." American Ethnologist 34 (4): 621-41. https://doi.org/ $10.1525 /$ ae.2007.34.4.621.

-_-. 2009. Alien Ocean: Anthropological Voyages in Microbial Seas. Berkeley: University of California Press. https://doi.org/10.1525/9780520942608.

- - . 2011a. "From Spaceship Earth to Google Ocean: Planetary Icons, Indexes, and Infrastructures." Social Research: An International Quarterly 78 (4): 1211-42.

-_-. 2011b. "Nature/Culture/Seawater." American Anthropologist 113 (1): 132-44. https://doi.org/10.1111/j.1548-1433.2010.01311.x.

- - 2016. Sounding the Limits of Life: Essays in the Anthropology of Biology and Beyond. Princeton: Princeton University Press. https://doi.org/10.1515/9781400873869.

Höhler, Sabine. 2014. "Die Weltmeere - Science und Fiction des Unerschöpflichen in Zeiten neuer Wachstumsgrenzen." Geschichte und Gesellschaft. Zeitschrift für Historische Sozialwissenschaft 40 (3): 437-51. https://doi.org/10.13109/gege.2014.40.3.437. 
International Science Council. 2020. "Call for Decade Actions for UN Decade of Ocean Science for Sustainable Development.” https://council.science/current/news/call-for-decade-actions-for-undecade-of-ocean-science-for-sustainable-development/.

Jue, Melody. 2020. Wild Blue Media: Thinking through Seawater. Durham: Duke University Press. https://doi.org/10.1215/9781478007548.

Klein, Bernhard, and Gesa Mackenthun, eds. 2004. Sea Changes: Historicizing the Ocean. New York: Routledge.

Klose, Alexander. 2015. The Container Principle: How a Box Changes the Way We Think. Cambridge: MIT Press.

Kurien, John. 2002. “People and the Sea: A 'Tropical-Majority' World Perspective.” Maritime Studies $1(1)$ : 9-26.

Lebreton, L., B. Slat, F. Ferrari, B. Sainte-Rose, J. Aitken, R. Marthouse, S. Hajbane, et al. 2018. "Evidence That the Great Pacific Garbage Patch Is Rapidly Accumulating Plastic.” Scientific Reports 8 (1). https://doi.org/10.1038/s41598-018-22939-w.

Lewis, Martin W. 1999. “Dividing the Ocean Sea.” Geographical Review 89 (2): 188-214. https://doi.org/10.2307/216086.

Mambra, Shamseer. 2019. "15 Brave Organisations Fighting To Save Our Oceans.” Marine Insight, 2019. https://www.marineinsight.com/environment/15-brave-organisations-fighting-save-oceans/.

Matsuda, Matt K. 2006. “The Pacific.” The American Historical Review 111 (3): 758-80. https://doi.org/10.1086/ahr.111.3.758.

McLuhan, Marshall, and Quentin Fiore. 1968. War and Peace in the Global Village: An Inventory of Some of the Current Spastic Situations That Could Be Eliminated by More Feedforward. New York: McGraw-Hill.

Mero, J.L. 1989. “Oceans.” In The New Encyclopaedia Britannica. Vol. 25. Chicago: Encyclopaedia Britannica.

Oldenziel, Ruth. 2011. "Islands: The United States as a Networked Empire.” In Entangled Geographies: Empire and Technopolitics in the Global Cold War, edited by Gabrielle Hecht, 13-42. Cambridge, MA: MIT Press. https://doi.org/10.7551/mitpress/9780262515788.003.0002.

Oreskes, Naomi. 2014. "Changing the Mission: From the Cold War to Climate Change.” In Science and Technology in the Global Cold War, edited by Naomi Oreskes and John Krige, 141-88. Cambridge, London: MIT Press. https://doi.org/10.7551/mitpress/9780262027953.003.0005.

Parks, Lisa, and Nicole Starosielski, eds. 2015. Signal Traffic: Critical Studies of Media Infrastructures. Urbana: University of Illinois Press. https://doi.org/10.5406/illinois/9780252039362.001.0001.

Perrin, Jacques. 2009. Oceans. Paris: Pathé.

Peters, John Durham. 2015. The Marvelous Clouds: Toward a Philosophy of Elemental Media. Chicago, London: University of Chicago Press. https://doi.org/10.7208/chicago/ 9780226253978.001.0001.

Reclus, Élisée. 1872. The Earth: A Descriptive History... Edited by H. Woodward. Translated by B. B. Woodward. New York: Harper.

Rozwadowski, Helen M. 2005. Fathoming the Ocean: The Discovery and Exploration of the Deep Sea. Cambridge, Mass: Harvard University Press. https://doi.org/10.4159/9780674042940.

- - . 2018. Vast Expanses: A History of the Oceans. London: Reaktion.

Sebille, Erik van. 2013. "Leave the Ocean Garbage Alone: We Need to Stop Polluting First." The Conversation, 2013. http://theconversation.com/leave-the-ocean-garbage-alone-we-need-to-stoppolluting-first-13537. 
Sebille, Erik van, Matthew H. England, and Gary Froyland. 2012. "Origin, Dynamics and Evolution of Ocean Garbage Patches from Observed Surface Drifters.” Environmental Research Letters 7 (4): 044040. https://doi.org/10.1088/1748-9326/7/4/044040.

Serres, Michel. 1977. La Distribution (Hermes IV). Paris: Les Editions de Minuit.

Shiga, John. 2013. "Sonar: Empire, Media, and the Politics of Underwater Sound." Canadian Journal of Communication 38 (3): 357-77. https://doi.org/10.22230/cjc.2013v38n3a2664.

- - . 2016. "Ping and the Material Meanings of Ocean Sound." In Sustainable Media: Critical Approaches to Media and the Environment, edited by Nicole Starosielski and Janet Walker, 128-45. New York: Routledge.

Starosielski, Nicole. 2015. The Undersea Network. Sign, Storage, Transmission. Durham: Duke University Press. https://doi.org/10.1215/9780822376224.

Starosielski, Nicole, and Janet Walker, eds. 2016. Sustainable Media: Critical Approaches to Media and Environment. New York: Routledge. https://doi.org/10.4324/9781315794877.

Steinberg, Philip E. 2001. The Social Construction of the Ocean. Cambridge University Press.

World Bank. 2012. Inclusive Green Growth: The Pathway to Sustainable Development. https://doi.org/ $\underline{10.1596 / 978-0-8213-9551-6 .}$ 